\title{
The influence of the conditions and worktime on the waste vanadic catalyst amount
}

\author{
Piotr Grzesiak, Rafał Motała, Marcin Grobela1, Mieczysław Trypuć, Krzysztof Mazurek ${ }^{2}$ \\ ${ }^{1}$ Institute Of Plant Protection, ul. Miczurina 20, 60-318 Poznań, Poland, e-mail: p.grzesiak@ior.poznan.pl \\ ${ }^{2}$ Nicolaus Copernicus University, Faculty of Chemistry, ul. Gagarina 7, 87-100 Toruń, Poland, \\ e-mail: trypuc@chem.uni.torun.pl
}

\begin{abstract}
This paper includes the research results of the vanadic catalyst study that was operated in PCC Rokita S.A. during a gaseous $\mathrm{SO}_{3}$ formation. The physical properties have been studied: mechanical strength, bulk density and grindability during the five-year cycle of the catalyst worktime. The studies presented underline the prediction of the amount of the formed vanadic waste material.
\end{abstract}

Keywords: vanadium catalyst, waste products.

Presented at VII Conference Wasteless Technologies and Waste Management in Chemical Industry and Agriculture, Międzyzdroje, 12 - 15 June, 2007.

\section{INTRODUCTION}

$\mathrm{SO}_{2}$ to $\mathrm{SO}_{3}$ oxidation process proceeds in converters of sulfuric acid system and gaseous $\mathrm{SO}_{3}$ systems. Such system operates among others in the PCC ROKITA SA in Brzeg Dolny, and the obtained gaseous $\mathrm{SO}_{3}$ is used for organic compound sulfonation that is applied for surfaceactive and detergent agents.

In such systems, $\mathrm{SO}_{2}$ is obtained due to sulfur combustion and all such systems operate strictly according to the single absorption process with the plate arrangement $(4+0)$.

The system discussed converter with the internal diameter $1.2 \mathrm{~m}$, runs with the following gas parameters: $6 \%$ $\mathrm{SO}_{2}, 15 \% \mathrm{O}_{2}, 79 \% \mathrm{~N}_{2}$ and the linear speed of gas flow: $\mathrm{V}=0.35 \mathrm{Nm} / \mathrm{s}$. The system of gaseous $\mathrm{SO}_{3}$ formation is composed of the preparation and sulfur combustion node as well as the contact one ${ }^{1}$ (Fig. 1). The preparation and sulfur combustion node consists of: sulfur melter, liquid sulfur proportioning pump, sulfur combustion furnace and heat exchanger for heat utilization from sulfur combustion. The contact node is composed of the converter and heat exchanger for the process gas cooling.

The manufacturing process runs as follows: the purification and drying of the air that is directed to the sulfur furnace where liquid sulfur combustion occurs. Sulfur contains some inorganic solid substance, ash, and the system does not contain an installation for sulfur filtration. As the consequence of sulfur combustion, $\mathrm{SO}_{2}$ is formed and it emits a significant amount of heat and the gas temperature increases up to $700^{\circ} \mathrm{C}$. Hot gas is directed through the air heater (1) to the hot gas filter, where gas emission from ash that comes from sulfur combustion should occur. $\mathrm{SO}_{2}$ to $\mathrm{SO}_{3}$ oxidation process occurs in the converter at four contact plates that are filled with the vanadic catalyst. During that process heat is emitted and gas temperature increases. After I plate, gas is cooled in the heat exchanger WC-3, while gas cooling after another two plates is realized without membrane, by dry cold air injection. Hot gas after IV plate is cooled in the air heater (3) and the heat exchangers WC-1 and WC-2. The cooled gas is directed to sulfonators. The heat from sulfur combustion and $\mathrm{SO}_{2}$ oxidation is used for air heating, which is directed for sulfur combustion, and for the dry air recovery.

Air-drying, which is directed to sulfur combustion, is carried out at the molecular sieve beds and the moisture content depends on the system efficiency. In the case of the technological regime observance, the moisture content in the gas should be lower than $0.02 \mathrm{~g} / \mathrm{Nm}^{3}$. Such amount ensures low material corrosion in the technological system. It significantly limits the unfavourable influence of corrosion products on the phase modifications in the active phase of the operated catalysts.

The converter in the system discussed has been filled with the low-resistance and Raschig ring-form catalyst at each plate since year 2000 (Table 1). Each layer was optimized up to the applied loading parameters. All the physico-chemical and catalytic properties were estimated before the catalyst loading to the converter.

\section{EXPERIMENTAL}

The systematic parameter estimation of the system running, based on $\mathrm{SO}_{2}$ concentration determination at each balance point, was done. On the basis of the obtained results, the system running parameters, which ensure a high productivity of $\mathrm{SO}_{2}$ oxidation during the whole production cycle, were optimized. The effective optimization was possible due to further evaluation of catalysts and the suitable proofs of plate filling. In order to succeed, the average catalyst samples were taken from top, middle and bottom plate layers and their physical properties were evaluated. The vanadic catalyst samples were examined after each year of operating in the converter. The chemical analysis and bulk density, compression resistance and grindability were determined. Studies were carried out according to the well-known and commonly used methodology devised by Sulfuric Acid Institution at The Institute of Plant Protection in Poznań ${ }^{2}$. Moreover, every time the sample identification was done, which relied on the evaluation of its appearance from the statement of the surface salting out phenomenon of the active phase components point of view, and it indicates the possibility of the granule mechanical strength degradation. 


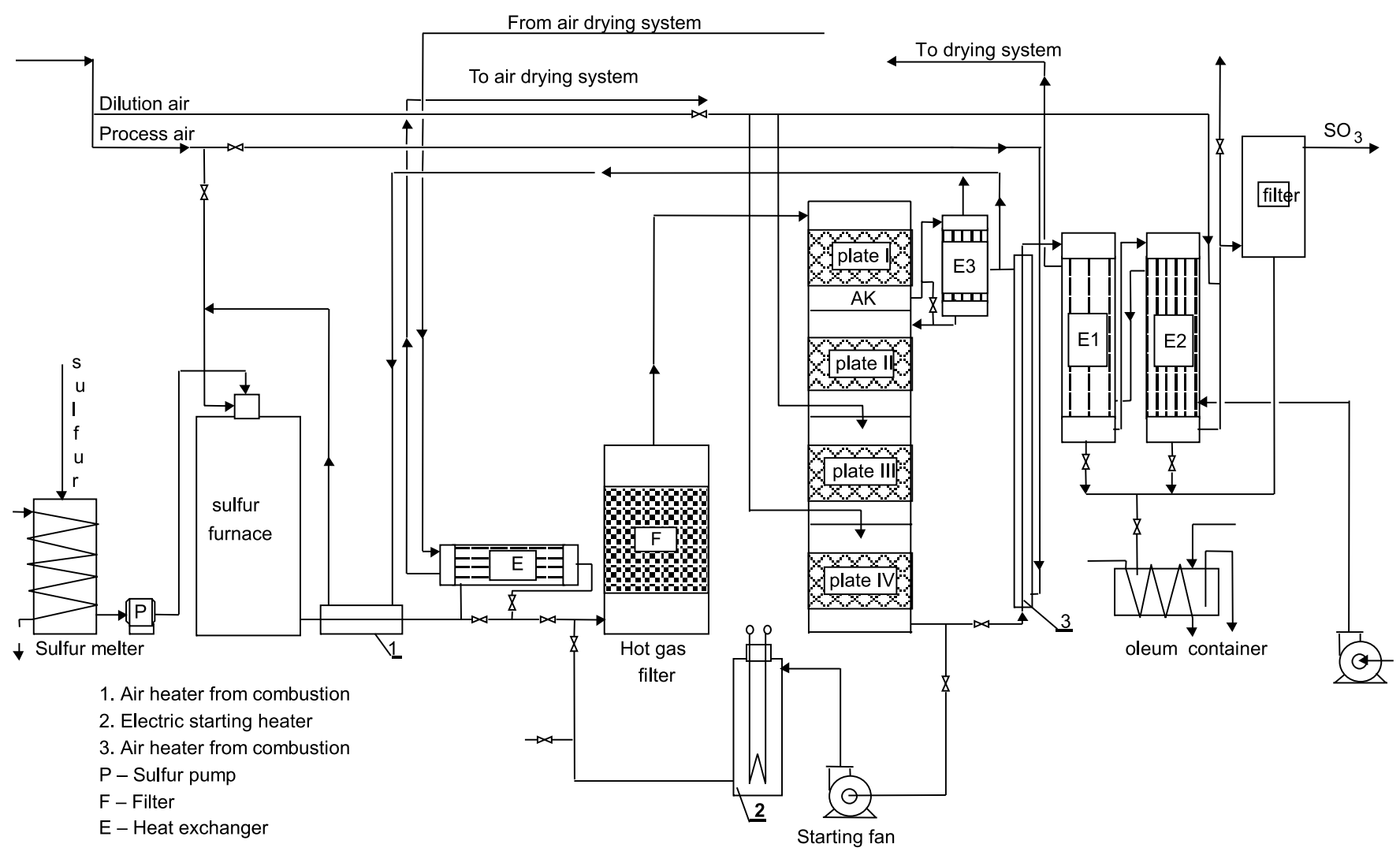

Figure 1. The flow diagram of the gaseous sulfur trioxide preparation system

Table 1. The vanadic mass distribution in the converter after the filling replacement

\begin{tabular}{|c|c|c|c|c|}
\hline Parametr & plate I & plate II & plate III & plate IV \\
\hline Catalyst type & MKH2-R11 & MKH2-R11 & MKH2-R11 & MKH2-R11 \\
\hline Granule diameter, $\mathrm{mm}$ & $11 / 4$ & $11 / 4$ & $11 / 4$ & $11 / 4$ \\
\hline Layer height, $\mathrm{m}$ & 0.50 & 0.50 & 0.60 & 0.75 \\
\hline Catalyst volume, $\mathrm{m}^{3}$ & 0.615 & 0.615 & 0.738 & 0.923 \\
\hline Catalyst mass, $\mathrm{kg}$ & 340 & 340 & 370 & 460 \\
\hline Total filling height, $\mathrm{m}$ & \multicolumn{4}{|c|}{2.35} \\
\hline Total filling volume, $\mathrm{m}^{3}$ & \multicolumn{4}{|c|}{2.891} \\
\hline Total fill ing mass, $\mathrm{kg}$ & \multicolumn{4}{|c|}{1470} \\
\hline
\end{tabular}

Concurrently, the amount of catalyst mesh fraction from each plate screening was registered.

\section{RESULTS AND DISCUSSION}

The bulk density describes the catalyst type and its physical condition, as well as its time and conditions of work. The catalysts with a small grain diameter are characterized by greater bulk density than the ones with a larger diameter. The granule length is the parameter strictly related to the vanadic catalyst diameter that is designed for the industrial operating. As the worktime increases, the catalyst physical consumption and bulk density increase. The bulk density increase causes enlarged hydraulic resistance of the catalytic layer in the converter, the conversion decrease and the increased $\mathrm{SO}_{2}$ emission, as well as the necessity of partial or entire catalyst replacement.

The presented studies demonstrate the modification of bulk density. As the catalyst worktime increases, the bulk density of all the analyzed catalysts systematically increase despite any modifications of plate filling. The largest changes are observed at I plate. The initial catalyst bulk density at I plate was about $0.45 \mathrm{~kg} / \mathrm{dm}^{3}$, while after fiveyears of operating it increased to $0.50 \mathrm{~kg} / \mathrm{dm}^{3}$ (Fig. 2). The situation at the other plates is different as the modi- fications are insignificant. Such nature of that parameter modification is a regularity that results from I plate conditions of running.

The grindability of all the studied catalysts corresponds with their mechanical strength. The grindability increases systematically as the catalyst worktime increases. The greatest changes of that parameter were observed at I plate of the converter, independently from the correction of plate filling. The initial grindability was $1.25 \%$, and after five-years of operating it increased to $1.87 \%$, which means that about $50 \%$ (Fig. 3). The grindability changes at the other plates are less significant. The smallest modifications occurred at IV plate of the converter, where the grindability increased by $15 \%$.

The catalyst grindability and its mechanical strength are the basic physical parameters of further usefulness defining of the catalyst operating and they are strictly related to inversely proportional dependence. As the grindability increases, the mechanical strength decreases. Each catalyst type has determined the limiting value of mechanical strength, below which the catalyst must be eliminated from operating. Such value describes the behaviour of the initial grain shape during its industrial operating and it influences the catalyst life, the hydraulic resistance of the contact layer that limits indirectly the possibility of high 
$\mathrm{SO}_{2}$ conversion due to excessive layer dustiness and the locking of reactant access to the catalyst surface. Further catalyst operating threatens the physical granule degradation, the significant increase of the plate hydraulic resistance and the possibility loss of gas forcing through the technological system.

The mechanical strength of the catalysts studied is different, depending on the place of work and it changes as the worktime increases, however the influence on the resistance value has plate-filling correction. Independently from the mentioned conditioning, the strength of the catalysts studied decreases as its worktime increases. The initial catalyst strength at I plate was $79 \mathrm{kG} /$ granule, while after five-years of operating it decreased to $47 \mathrm{kG}$ /granule

(Fig 2). Despite the performed corrections in plate filling, the strength decreased by $40 \%$ but it still locates above the limiting value for that catalyst. The strength at II plate decreased by $32 \%$, III plate $-28 \%$, and at IV plate $-17 \%$ from 80 to $67 \mathrm{kG} /$ granule. Owing to the corrections in plate filling, the mechanical strength of all the catalysts studied was above the limiting value and such a tendency of modifications was expected.

The mechanical strength modifications of the catalyst that was operated in the gaseous $\mathrm{SO}_{3}$ system in PCC ROKITA are the function of the catalyst worktime. The amount of the formed waste material during five years is equivalent to the amount of the productive mesh fraction.

The chemical constitution of the catalyst studied is different and it depends on the initial contents of the active phase components in the catalyst and those component contents in the supplementary catalyst of screening losses. Vanadium contents after five years of catalyst worktime ranges from 5.10 to $6.10 \% \mathrm{~V}_{2} \mathrm{O}_{5}$, potassium

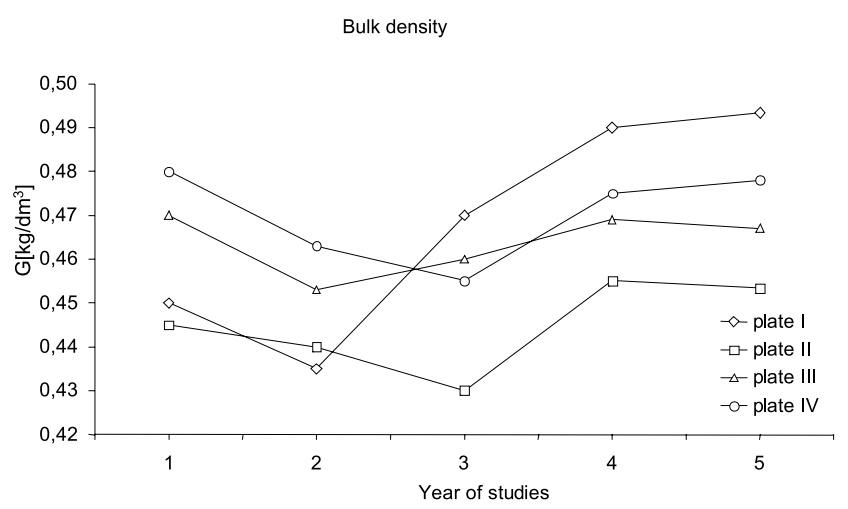

Figure 2. The catalyst bulk density in the successive years of studies

Grindability

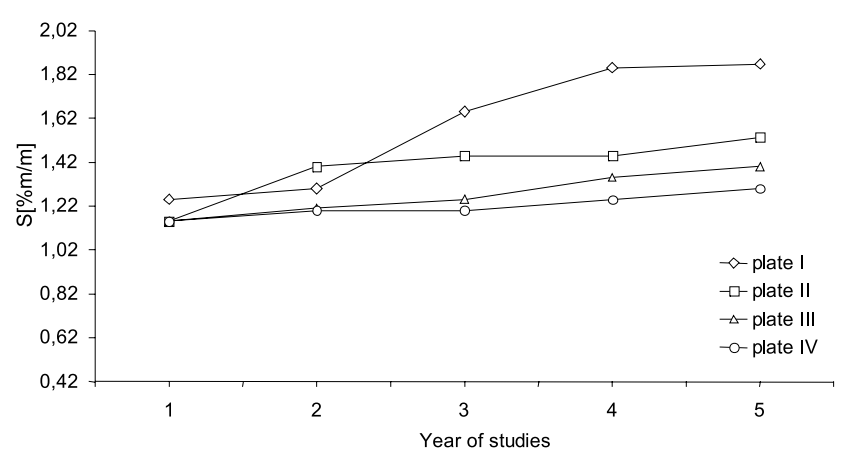

Figure 3. The catalyst grindability in the successive years of studies

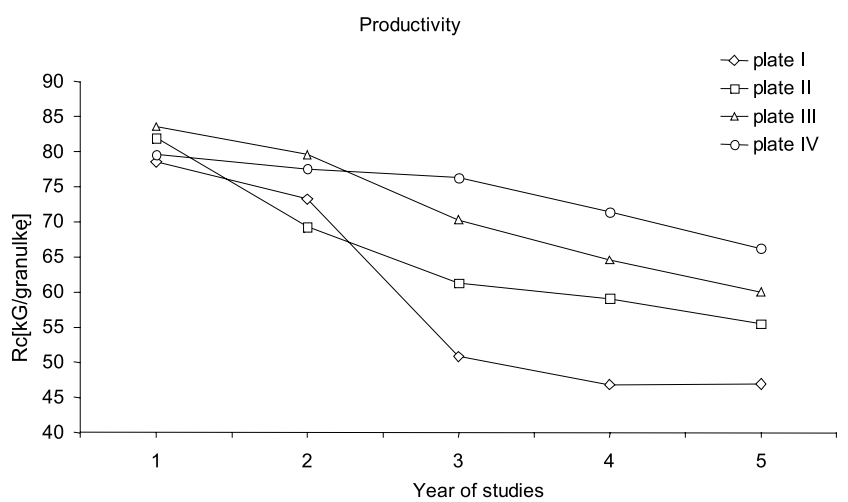

Figure 4. The catalyst mechanical strength in the successive years of studies

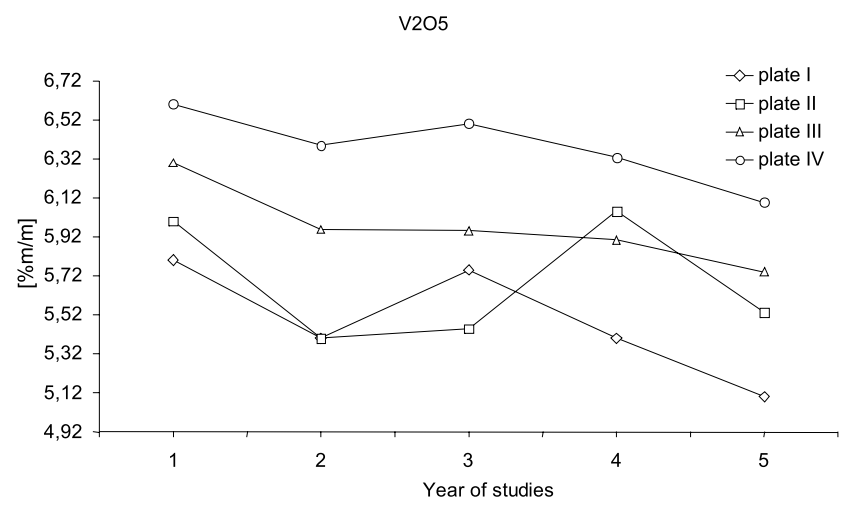

Figure 5. The vanadium contents in catalysts in the successive years of studies

$\mathrm{K} 2 \mathrm{O}$

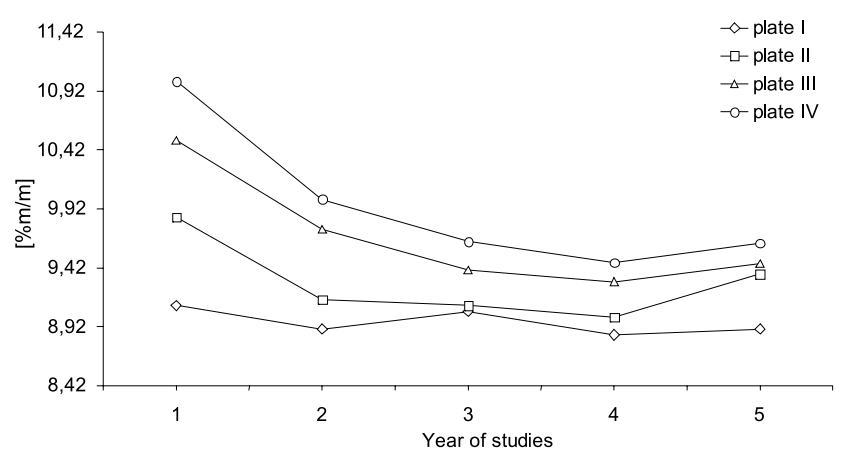

Figure 6. The potassium contents in catalysts in the successive years of studies

from 8.90 to $9.63 \% \mathrm{~K}_{2} \mathrm{O}$. The greatest chemical analysis changes of the active phase occur at the first two plates of the converter. However, those plates are often supplemented by mass due to screening, which partly limits the range of changes. Vanadium contents decreases as the catalyst worktime increases. Potassium contents is also lower. It indicates the modifications that occur in the catalyst active phase during its worktime (Fig. 5, 6).

The modifications of the active phase contents are not significant enough to cause the catalyst elimination due to its excessive catalytic inactivation. The sample identification, run each time when physical properties were studied, did not indicate worrying changes in the granule appearance. The surface salting out of the active phase components was not found, other blocks than the initial ones were observed in some but not alarming amount (indication for the mechanical strength worsening). It indicates 
that the catalyst waste material, formed during the studies, is not the result of the necessity of the catalyst replacement due to its properties worsening, but the result of mass screening.

The amount of mesh fraction is as following: I plate about $3.4 \%$, II one $1.7 \%$, III one $1.4 \%$, while IV one is only $0.9 \%$. All in all, the catalyst waste material composes $7.34 \%$ of total filling mass, which is about $108 \mathrm{~kg}$.

\section{CONCLUSIONS}

As the result of the industrial vanadic catalyst operating, some waste material is formed that cannot be reused.

In the discussed system during the five-year of operating, the catalyst waste material originates not from the necessity of the catalyst elimination due to its further uselessness, but from mass screening.

The amount of the obtained waste material is not large as it amounts to below $10 \%$ of the loaded catalyst mass.

\section{ACKNOWLEDGMENTS}

This work was supported by science resources (20072010) under Research and Development Project No. R05 03502.

\section{LITERATURE CITED}

(1) Kluska R., Kopertowski J., Grzesiak P., Woźniak A., Grobela M.: Badanie wydajności termodynamicznej aparatu kontaktowego w PCC Rokita Brzeg Dolny, Kwas siarkowy na progu integracji europejskiej, 2001, 231 - 238.

(2) Grzesiak P. (Editor): Metody oceny katalizatorów wanadowych do utleniania $\mathrm{SO}_{2}$. 